\section{O FATO}

Aos 16 de abril de 1996, o ilustre Governador do Estado de São Paulo ajuizou ação direta de inconstitucionalidade impugnando a constitucionalidade do artigo $101 \mathrm{da}$ Constituição do seu Estado na parte reproduzida em negrito,

“vinculam-se à Procuradoria Geral do Estado, para fins de atuação uniforme e coordenada, os órgãos jurídicos das autarquias, incluindo as de regime especial, aplicando-se a seus procuradores os mesmos direitos $e$ deveres, garantias e prerrogativas, proibições e impedimentos, atividade correicional, vencimentos, vantagens e disposiçōes atinentes à carreira de Procurador do Estado, contidas na Lei Orgânica de que trata o art. 98 , parágrafo único, desta Constituição".

É a Adin 1434-0/600. Em petição de 30 de abril, protocolada a 3 de maio, reduziu a impugnaçāo a duas palavras, do art. 101, "ven- cimentos, vantagens". $\mathrm{O}$ autor entende que elas ofendem o art. 37, XIII, da Constituição Federal, "é vedada a vinculação de vencimentos, para o efeito de remuneração do serviço público", e o art. 61, § 1, II, "a". "compete ao Presidente da República a iniciativa de projetos de lei que disponham sobre criação de cargos, funçōes ou empregos públicos na administração direta ou autárquica ao aumento de sua remuneração".

\section{A CONSUlTA}

1. A referência a "vencimentos, vantagens", no art. 101 da Constituiçāo de São Paulo, está em conflito com os artigos 37, XIII e 61; § 1², II, a, da Constituição Federal?

2. O tratamento pecuniário atribuído aos procuradores de autarquias, desde antes da Constituição de 1989, configura direito adquirido ou pode ser apagado?

e desenvolvimento de seus objetivos institucionais, apresentando, anualmente, relatório circunstanciado de suas atividades ao Instituto Nacional de Seguro Social; e VI - não percebam seus diretores, conselheiros, sócios, instituidores, benfeitores, ou equivalentes, remuneração, vantagens ou benefícios, por qualquer forma ou título, em razão das competências, funçōes ou atividades que lhe são atribuídas pelo respectivo estatuto social.

$\$ 1^{2}$. Para os fins deste artigo, entende-se por assistência social beneficente a prestação gratuita de benefícios e serviços a quem destes necessitar". 


\section{EMENTA}

O art. 101 da Constituição de São Paulo é de imaculada constitucionalidade, não conflitando, direta ou indiretamente, com os artigos 37, XIII e 61, § 1, II, “a”, da Constituiçāo Federal.

$O$ questionado artigo $101 \mathrm{em}$ nada inovou o sistema legal do Estado, tendo se limitado a reafirmar preceitos há muito consagrados em lei.

A Constituição, normalmente, não constitui uma ruptura com o sistema jurídico preexistente, revogando apenas o que com ela for incompativel.

O tratamento legal à administração direta e à indireta há de ser coerente, pois a pluralidade de agentes administrativos nāo compromete nem pode comprometer a unidade da administraçăo. No serviço jurídico do Estado de São Paulo, em especial, é explícita a unidade orgânica e funcional de seus segmentos, sob a expressa supervisão da Procuradoria Geral do Estado, artigos 98 e 101.

\section{PARECER}

1. A ação direta de inconstitucionalidade é uma ação nobre, nobre porque seu objeto envolve sempre uma questão de alto quilate jurídico, a legalidade da lei ou de sua validade em face da lei maior, nobre porque reservada pela Constituição a poucas autoridades ou entidades, e nobre porque começa e termina no plenário do mais alto tribunal da nação. No entanto, a despeito de seu excepcional relevo no armazém judiciário, nem sempre tem sido usada com sobriedade. A pressa, se não estou em erro, responde por algumas ações articuladas de maneira imprópria à sua relevância, colocando por vezes em termos menos corretos os problemas a enfrentar e enquadrando-os de maneira defectiva e quiçá inadequada, dificultando, senão comprometendo, a correta solução.

2. Da ação ajuizada pelo ilustre Governador do Estado de São Paulo não se pode dizer tenha havido pressa. A Constituição é de 1989 e a açāo foi aforada em 1996. No entanto, também não se pode dizer que tenha sido preparada com o lavor que seria de esperar vinda de um Estado onde é rico o tesouro de sua cultura jurídica. Basta notar que a inicial é datada de 16 de abril de 1996 e questionou o art. 101 da Constituição ao estabelecer que os órgãos jurídicos das autarquias não só estāo vinculados à Procuradoria Geral do Estado "para os fins de atuação na forma uniforme e coordenada" como a eles são aplicados "os mesmos direitos e deveres, garantias e prerrogativas, proibiçōes $e$ impedimentos, atividade correicional, vencimentos, vantagens $e$ disposiçōes atinentes à carreira de Procurador do Estado"; todas essas "expressões" a ação pretendeu que o STF expungisse do art. 101 da Constituição de São Paulo por infringentes à Constituição da República.

3. Duas semanas após, em petição de 30 de abril, protocolada a 2 de maio, o autor da ação reduziu as "expressões" supostamente viciadas a duas "vencimentos, vantagens". As outras que a 16 de abril seriam inconstitucionais deixavam de sê-lo a $\mathbf{3 0}$ do mesmo mês. Isto mostra a facilidade com que se vai ao Supremo Tribunal Federal para pedir que ele derrogue o disposto pelo legislador constituinte estadual, como se pouco sentido tivesse o princípio federativo, enfaticamente proclamado pela Constituição federal.

\section{O PRIMEIRO FUNDAMENTO}

4. A alegada inconstitucionalidade das palavras "vencimentos vantagens", do art. 101 da Constituição de São Paulo decorreria da norma do art. 37, XIII, segundo a qual "é vedada a vinculação ou equiparação de vencimento para o efeito de remuneração de pessoal do serviço público, ressalvado o disposto no inciso anterior e no art. $39 \$ 1$."

5. A meu juízo nāo procede a alegaçāo, a vinculação estabelecida é entre os serviços jurídicos das autarquias e o serviço jurídico do Estado, para o fim declarado "de atuação uniforme e coordenada", o que, de tão óbvio, chega a ser desnecessário. Seria insigne contra-senso que a atuação dos serviços jurídicos 
do Estado e de suas autarquias fosse incoordenada e contraditória.

Não me parece exista relação entre a norma do art. 37, XIII, da Constituição Federal. e o art. 101 da Constituição do Estado, segundo o qual

"vinculam-se à Procuradoria Geral do Estado para fins de atuação uniforme e coordenada, os órgãos jurídicos das autarquias, incluindo as de regime especial, aplicando-se a seus procuradores os mesmos direitos $e$ deveres, garantias e prerrogativas, proibif̧ões e impedimentos, atividade correicional, vencimentos, vantagens e disposiçöes atinentes à carreira de Procurador do Estado, contidas na Lei Orgânica de que trata o art. 98, parágrafo único, desta Constituição".

A impugnação, baseada em uma palavra, faz lembrar sentença de HOLMES, em Gompers v. U.S., ao notar que o sentido de uma provisão constitucional nāo se apreende com o exame de palavras e o auxílio de um dicionário,

" but the provisions of the Constitution are not mathematical formulas having their essence in their form; ... Their significance is vital not formal; it is to be gathered not simply by taking the words and a dictionary, but by considering their origin and the line of their growth",

233 US 605 e 610.

\section{SUBORDINAÇÃO NORMAL E NECESSÁRIA}

6. Com efeito, o vocábulo em que se funda a impugnação, "vinculam-se", há de ser entendido no contexto do preceito e não dele separado; a Constituição paulista diz se vinculam, verbis,

"vinculam-se à Procuradoria Geral do Estado, para fins de atuação uniforme e coordenada, os órgãos juridicos das autarquias..."

7. A "vinculação" em causa não é nem mais, nem menos, que a sujeiçāo da entidade autárquica à pessoa que a criou; é o que em doutrina se denomina "tutela administrativa" ou "controle autárquico". TITO PRATES
DA FONSECA, Direito Administrativo. 1943, n 51, pág. 89: TEMÍSTOCLES CAVALCANTI, Princípios de Direito Administrativo, 1945, pág. 255; CELSO ANTONIO BANDEIRA DE MELO, Curso de Direito Administrativo, 1966, pág. 89, HELY LOPES MEIRELLES, Direito Administrativo, 1986, pág. 286 e 292, LÚCIA VALLE FIGUEIREDO, Curso de Direito Administrativo, 1994, pág. 89 , sem o que a autarquia deixaria de ser autarquia; por ser autárquica a entidade criada pelo Estado não fica solta no espaço e sem vínculos com a pessoa que a tenha criada; integra a administração e, obviamente, há de guardar coerência e sujeição à pessoa donde tenha se originado; "vincular" não chega a ser uma palavra aidética, a contaminar tudo o que toca, nem traz em si, necessariamente, o germe da inconstitucionalidade. $O$ art. $101 \mathrm{da}$ Constituição de São Paulo limita-se a dizer o óbvio ao proclamar que os serviços jurídicos das autarquias vinculam-se à Procuradoria Geral do Estado; estranho seria que se vinculassem à Secretaria de Saúde ou que não estivessem vinculados a nenhum órgão do Estado e atuassem soberanamente, como se fossem um quarto ou quinto Poder do Estado; substitua-se a palavra amaldiçoada, ponha-se subordinaçāo em vez de vinculação e o problema, no meu modo de ver artificial, deixa de existir, e tanto vale dizer que os órgãos jurídicos das autarquias vinculam-se à Procuradoria Geral do Estado como enunciar que eles estão subordinados a ela e sujeitos à sua disciplina e à sua superior orientação. A amaldiçoada "vinculação", em se tratando de autarquia, é mais do que normal, chega a ser necessária, para nāo dizer obrigatória, pois é inafastável; em uma palavra, é inerente à relação da criatura com o criador. Seria um disparate que os serviços jurídicos das autarquias permanecessem independentes do serviço jurídico do Estado, representado por sua Procuradoria Geral, e sendo independentes pudessem colocar-se em antagonismo com a orientação dela. Poder-se-ia conceber que os órgãos jurídicos das autarquias, em juízo ou administrativamente, sustentassem posições contrárias aos defendidos pelo Estado mediante a sua Procuradoria Geral ou a orienta- 
ção há de ser uniforme, coerente, harmoniosa, sem que a lei necessite dizer?

Ao demais, convém se tenha presente o art. 98 da mesma Constituição do Estado de Sāo Paulo,

"A Procuradoria Geral do Estado é instituiçāo de natureza permanente, essencial à Administração Pública Estadual, vinculada diretamente ao Governador, responsável pela advocacia do Estado, da Administração direta e autarquias e pela assessoria e consultoria jurídica do Poder Executivo, sendo orientada pelos princípios da legalidade e da indisponibilidade do interesse público."

8. Depois de solenizar a vinculação ou a subordinação dos serviços jurídicos das autarquias à Procuradoria Geral do Estado, a Constituição acrescenta o óbvio, aditando, analiticamente, o que já estava enunciado na regra inicial: sendo idênticos os serviços, em tudo e por tudo haveria de ser igual o tratamento dado a eles, nem mais, nem menos. Assim haveria de ser mesmo que a Constituição de São Paulo fosse silente, a menos que a autarquia fosse soberana, e não fosse autarquia, o que seria outro contra-senso

\section{CRIATURA DO ESTADO}

9. Sendo criatura do Estado, nada mais natural que exista uma relação de paridade entre Estado e autarquia por ele criada.

10. Ao criar a autarquia, o Estado pretende, mediante uma técnica descentralizadora, obter maior eficiência e melhor desempenho no setor escolhido; não fora assim e não teria sentido autarquizar este ou aquele segmento da administração; no entanto, essa alteraçāo, sob o ponto de vista do Direito que lhe é próprio, é mais superficial do que real, mais aparente do que substancial, pois o conteúdo da administração continua idêntico.

Devendo sua existência ao Estado, a autarquia atua como longa manus dele, inteiramente devotada à administração pública; por motivo de conveniência e oportunidade, o Estado desloca um segmento seu, dá-lhe autonomia administrativa e financeira, patrimônio e personalidade, para que melhor desempenhe ati- vidade estatal: sempre se entendeu assim, no plano doutrinário, v.g. TITO PRATES DA FONSECA, op. cit., n² 50 a 56, pág. 87 a 100; TEMÍSTOCLES BRANDÃO CAVALCANTE, op. cit., $n^{2} 220,223$, pág. 253 e segs.; RUY CIRNE LIMA, Princípios de Direito Administrativo, $1987, \S 8$, pág. 61 a 65 ; id. Sistema de Direito Administrativo, 1953, I, § $2^{2}, \mathrm{n}^{2} 10$, pág. $23, \S 15, \mathrm{n}^{2} 3$ a 6 , pág. 138 a 145; HELY LOPES MEIRELLES, op. cit., pág. 285 a 295; CELSO ANTONIO BANDEIRA DE MELLO, op. cit., pág. 86 a 92; LÚCIA VALLE FIGUEIREDO, op. cit., III, $\mathrm{n}^{\circ} 4$, pág. 79 a 85 , como no plano legal, Decreto-lei 6.016 , de 1942, art. 20, Lei 830 , de 1949, art. 139, Decreto-lei 200, de 1967, art. 4, II, a, 50, I:

"A Administração Federal compreende: II. A Administração Indireta, que compreende as seguintes categorias de entidades, dotadas de personalidade jurídica própria: a) Autarquias "Para os fins desta lei, considera-se: I. Autarquia - o serviço autônomo, criado por lei, com personalidade jurídica, patrimônio e receita próprios, para executar atividades tipicas da Administração Pública, que requeiram, para seu melhor funcionamento, gestão administrativa e financeira descentralizada."

Como o Estado que a cria, a autarquia é pessoa jurídica de Direito Público, e como

"todas as pessoas administrativas denotam uma adequação específica à atividade da administração pública";

Daí, e a propósito, a advertência de RUY CIRNE LIMA,

"a unidade da ação, malgrado a pluralidade dos agentes, é um dado ontológico", Sistema de Direito Administrativo, 1953, §15, pág. 139.

11. Após estabelecer a vinculação dos órgãos jurídicos das autarquias à Procuradoria Geral do Estado, ou a sua subordinação explícita fundada no principio da tutela administrativa inerente à entidade autárquica, "para fins de atuaçäo uniforme e coordena$d a$ ", acrescenta, analiticamente, "aplicandose a seus procuradores os mesmos direitos $e$ deveres, garantias e prerrogativas, proibições e impedimentos, atividade correicional, 
vencimentos, vantagens e disposições atinentes à carreira de Procurador do Estado".

Se a autarquia é um segmento do serviço público, dele separado para atuar com certa autonomia, mas sob tutela, sem deixar de ser serviço público, à autarquia haveria de aplicar-se fundamentalmente a disciplina legal aplicável à administração, de que é originária.

\section{A MESMA DISCIPLINA LEGAL}

12. A Constituição Federal, nada menos que a Constituição, é expressa a respeito, em várias de suas normas, v.g.,

(a) ao dispor acerca "da Administração Pública", logo no art. 37 , risca energicamente as suas linhas fundamentais ao prescrever que

" $a$ administração pública direta, indireta ou fundacional, de qualquer dos Poderes da União, dos Estados, do Distrito Federal e dos Municípios obedecerá aos princípios de legalidade, impessoalidade, moralidade, publicidade..."

(b) e em diversas normas estabelece inequívoco paralelismo entre o servidor público e o servidor autárquico,

art. $61, \S 1 \stackrel{1}{1} I 1, a$, "são de iniciativa privativa do Presidente da República as leis que disponham sobre a criação de cargos, funções ou empregos públicos na administração direta e autárquica ou aumento de sua remuneraçāo";

(c) depois de asseverar, no art. 37, XVI,

" $e$ vedada a acumulação remunerada de cargos públicos, exceto quando houver compatibilidade de horários", em três hipóteses, que enumera, completa no inciso seguinte, o de $n^{\prime} X I I$, "a proibição de acumular estendese a empregos e funções $e$ abrange autarquias, empresas públicas, sociedades de economia mista e fundaçōes mantidas pelo poder público"

(d) segundo o art. 37, XIX,

"somente por lei especifica poderão ser criadas empresas públicas, entidades de economia mista, 'autarquias' ou fundação pública", e no inciso $X X$, "depende de autorização legislativa em cada caso, a criação de subsidiárias das entidades mencionadas no inciso anterior, assim como a participação de qualquer delas em empresa privada";

(e) prescreve o art. 39 que

“a União, os Estados, o Distrito Federal e os Municípios instituirão, no âmbito de sua competência, regime jurídico único e planos de carreira para os servidores da administração pública direta, das autarquias e das fundaçōes públicas"; A Lei 8.112, de 11.12.90, por sua vez,

"dispõe sobre o regime juridico dos servidores públicos civis, da União. das autarquias $e$ das fundações públicas federais";

(f) conforme o $\$ 2^{2}$ do artigo 150 ,

a imunidade recíproca entre a Uniāo, Estados, Distrito Federal e Municípios, consagrada no art. 150, VI, " $a$ ", é estendida às autarquias;

(g) 0 art. 163, II,

"lei complementar disporá sobre dívida pública externa e interna, incluindo a das autarquias";

(h) o art. $144, \S 12$, dispõe que

"a polícia federal.... destina-se a l, apurar infrações penais ... em detrimento de bens, serviços e interesses da Uniāo ou de suas entidades autárquicas..."e

(i) segundo o art. 109, I,

"aos juizes federais compete processar $e$ julgar: I. as causas em que a União, 'entidade autárquica' ou empresa pública... interessadas na condição de autoras, rés, assistentes ou opoentes...."

(j) conforme o art. $37 \S 6^{\circ}$,

a responsabilidade civil das autarquias tem a mesma disciplina que as demais pessoas jurídicas de direito público,

(k) os atos contratos por ela celebrados estão sujeitos à licitaçāo, art. 37, XXI, suas contas sujeitas ao Tribunal de Contas, art. 70 ;

(I) seus atos podem ser judicialmente questionados por ação popular, art. 5, LXXIII,

(m) até o prazo prescricional em favor $d a$ Fazenda Pública beneficia igualmente as autarquias, Decreto-Lei 4.597, de 1942.

(n) $O$ regime jurídico dos bens das autarquias é o mesmo dos bens públicos, - inalienabilidade, impenhorabilidade, imprescri- 
tibilidade, HELY LOPES MEIRELLES, op. cit. pág. 290 e 291.

13. É de intuitiva compreensāo que deva ser coerente o tratamento legal dado à administração direta e à indireta, pois a pluralidade de agentes administrativos não compromete nem pode comprometer a unidade da administração, e no serviço jurídico, em especial, é explícita a unidade orgânica e funcional de seus segmentos, sob a supervisão formal e expressa da Procuradoria Geral do Estado, Constituição estadual, arts. 98 e 101.

\section{PARALELISMO}

14. Como pessoa administrativa, a autarquia é em tudo e por tudo equiparada à pessoa que a tenha criado, União, Estado, Distrito Federal ou Município; como segmento da administração pública está sujeita às suas regras; até dos prazos processuais em dobro e em quádruplo se beneficiam as autarquias. Por tudo, os órgãos jurídicos das autarquias haveriam de ter o mesmo tratamento que os órgãos jurídicos do Estado, se o Estado é o criador da autarquia, se a autarquia é criatura do Estado, a equivalência no tratamento de ambos é decorrência da equivalência de situaçōes; irracional seria que os serviços jurídicos autárquicos não tivessem relação com o serviço jurídico do Estado ou fossem discriminados como se concorrentes desafetos; tratá-los desigualmente é que seria tisnar a Constituição, que consagra a igualdade perante a lei como dogma supremo.

15. Como foi notado, de início, a ação impugnava todos os itens que, por análise, fixa as relações entre os dois serviços jurídicos, colocados em plano de igualdade; depois, houve uma ablação no pedido e a impugnaçāo se circunscreveu a duas palavras e uma vírgula, "vencimentos, vantagens".

16. Desse modo, no tocante a "direitos $e$ deveres" o enunciado é lícito; no que concerne a "garantias e prerrogativas", passa incólume; no que se refere a "proibições e impedimentos", é incensurável; no que diz respeito "a atividade correicional", nada há a opor; a norma é perfeita ao referir-se às "disposi- ções atinentes à carreira", o que era inconstitucional a 16 de abril de 96 deixou de sê-lo a 30 do mesmo mês; no entanto, quanto à cláusula "vencimentos, vantagens" a nódoa é indelével...

17. Segundo velha regra da hermenêutica deve ser afastada, por irracional, a exegese que leva ao absurdo e me parece absurdo manifesto aceitar a igualdade de

"direitos e deveres, garantias e prerrogativas, proibiçōes e impedimentos, atividade correicional, disposições atinentes à carreira,

e repudiar a igualdade no que se refere a "vencimentos, vantagens".

18. Chega a ser chocante que os procuradores autárquicos sejam equiparados aos procuradores do Estado quanto a

direitos e deveres,garantias e prerrogativas,proibiçōes e impedimentos, atividade correicional.

disposições atinentes à carreira,

dados os laços umbilicais que unem uns a outros, mas que devam ser desigualmente tratados em relação a

"vencimentos, vantagens".

e que essa cláusula seja aquinhoada com a mais alta das ilegalidades que é a inconstitucionalidade.

19. Separam-se do texto constitucional duas palavras e contra elas se alega ofensa à Constituição, quando

" não se interpretam as leis por palavras ou frases isoladas", MAXIMILIANO, Comentários à Constituição, 1929, n 74, pág. 105.

e nāo perderam atualidade as observaçōes de STORY,

"but the most important rule is, that a constitution of governement does not, and cannot from its nature, depend in any great degree upon mere verbal criticism, or upon the import of single words", On the Constitution, 1891 , I, § 455, pág. 348.

\section{O ARGUMENTO A CONTRÁRIO}

20. Dir-se-á que o $\S 1^{\circ}$ do art. 39 da Constituição preceitua que "a lei assegurará, aos 
servidores da administraçāo direta, isonomia de vencimentos para cargos de atribuiçōes iguais ou assemelhados do mesmo Poder ou entre servidores dos Poderes Executivo, Legislativo e Judiciário, ressalvadas as vantagens de caráter individual $e$ os relativos à interesse ou ao local de trabalho", e que, mencionando a administração direta, silencia quanto à indireta; em verdade, nem precisava repetir o que está dito em vários artigos da mesma Constituição e esta deve ser interpretada como um complexo, orgânico e sistemático.

21. Depois de acentuar o desprestígio do argumento a contrário, "muito pretigioso outrora, mal visto hoje pela doutrina, pouco usado pela jurisprudência", salienta MAXIMILIANO,

"o brocardo - inclusio unius alterius est exclusio, como todo argumento a contrário, exige, talvez, ainda maior e mais discreta reserva da parte de quem o empregue no $\mathrm{Di}$ reito Constitucional, do que se reclama em se tratando de Direito Privado", Hermenêutica e Aplicação do Direito, 1941, n 296 e 379, pág. 291 e 371; Comentários à Constituição, $1929, n^{\circ} 83$, pág. 111; no mesmo sentido, STORY, op. cit., I, § 448, pág. 348, PONTES DE MIRANDA, Comentários à Constituiçāo de 1967, III, pág. 423.

\section{O SEGUNDO FUNDAMENTO}

22. Também é argüida a inconstitucionalidade do art. 101 da Constituição de São Paulo em face do que dispōe o art. $61, \S 1^{\circ}$, II, a, da Constituiçāo Federal, segundo o qual

"são de iniciativa privativa do Presidente da República as leis que disponham sobre criação de cargos, funções ou empregos públicos na administração direta $e$ autárquica ou aumento de sua remuneração".

Ainda menos razoável me parece a fundamentação encontrada para impugnar a constitucionalidade do art. 101 , da Constituição paulista, uma vez que ele, nem direta, nem indiretamente, cria cargos, funçōes ou empregos públicos, seja na administração direta, seja em autarquias, e nem aumenta sua remu- neração. Não existe sequer pertinência entre as matérias tratadas. A competência privativa do Governador do Estado, à semelhança da competência exclusiva do Presidente da República, no que tange à criação de cargos, funções ou empregos públicos, tanto na administraçāo direta como nas autarquias estaduais, permanece intocada e incólume, e está consagrada no artigo $24 \S 2^{\circ}$,

"Compete exclusivamente ao Governador do Estado a iniciativa das leis que disponham sobre:

I - criação e extinçāo de cargos, funçōes ou empregos públicos na administração direta e autárquico, bem como a fixação da respectiva remuneração."

\section{IRREDUTIBILIDADE - ART. 37, XV}

23. A impugnação à cláusula relativa a "vencimentos, vantagens" prende-se à chamada "verba honorária", também percebida pelos Procuradores do Estado. No entanto, se os procuradores autárquicos fazem jus à verba honorária não é devido ao art. 101 da Constituiçāo do Estado, mas ao inciso XV do artigo 37 da Constituição Federal, que estabeleceu a irredutibilidade dos vencimentos civis e militares, Constituição anterior à Carta paulista, que esta não poderia contrariar e tem de obedecer.

24. Com efeito, a verba honorária estava integrada no patrimônio jurídico e funcional dos procuradores autárquicos antes de promulgada a Constituição do Estado $e$ independente dela, $\mathrm{e}$, por conseguinte, mesmo que ela nāo contivesse o questionado art. 101 . Dispondo como dispôs, a Constituição paulista apenas incorporou ao seu texto o direito estadual vigente fazia 20 anos ou mais. Foi a esta situação que a Constituição Federal veio estender o pálio da sua autoridade e proteção.

25. Se "os vencimentos dos servidores públicos, civis e militares, sāo irredutiveis", como afiança o inciso XV do art. 37 da Lei Maior, os vencimentos dos procuradores autárquicos desde antes da Constituição paulista de 1989, regulados em lei antes mesmo da Constituição Federal de 1988, não podiam ser 
reduzidos. Irredutível é o que não pode ser reduzido, tanto na linguagem vulgar, como na linguagem jurídica. A diminuição, seja ela qual for, importa em redução.

26. Parece-me induvidoso esse ponto, motivo por que não vejo como se possa impugnar a constitucionalidade do art. 101, que deve ser visto e examinado em harmonia com a Constituição em seu todo, e não, anatomicamente, palavra por palavra, COOLEY, Constitutional Limitations, 1903, pág. 91; BLACK, Construction and Interpretation of the Laws, $1896, n^{\circ} 74$, pág. 166; WILLOUGHBY, Constitutional Law, 1929, I, § 40, pág. 65, MAXIMILIANO, Comentários à Constituição, $1929, n^{\circ} 74$, pág. 105, Corpus Juris Secundum, Constitutional Law, 1956, v. $16 \S 23$, pág. $91 ; 1984$, v. $16 \S 27$, pág. 87.

\section{O ART. 17 DO ADCT}

27. Nem se alegue com o disposto no art. 17 do ADCT, segundo o qual "os vencimentos, a remuneração, as vantagens e os adicionais, bem como os proventos de aposentadoria que estejam sendo percebidos em desacordo com a Constituição serão imediatamente reduzidos aos limites dela decorrentes, não se admitindo, neste caso, invocação de direito adquirido ou percepção de excesso a qualquer título". A verba honorária que os procuradores autárquicos percebiam era igual ao que percebiam os procuradores do Estado, de modo que, a menos que estes estivessem percebendo quantias indevidas à luz da Constituição, o que ninguém alegou, os procuradores autárquicos também nāo poderiam estar recebendo "em desacordo com a Constituição". Ou o que seria constitucional quanto aos Procuradores do Estado seria inconstitucional em relação aos Procuradores autárquicos, como se o oficio não fosse o mesmo, e como se uns e outros nāo integrassem a mesma administração estadual.

Passados quase sete anos da promulgação da Constituição estadual e quase oito da Constituição Federal, a ação direta 1.434 veio impugnar a equivalência de "vencimentos, vantagens" entre procuradores autárquicos e Pro- curadores do Estado, como se não houvesse relação entre eles, de resto, a mais íntima das relações.

\section{O ARTIGO 96 DA CARTA DE 1967}

28. Aliás, convém nāo esquecer que a regra do inciso XIII do art. 37 da Constituição, não é novidade desse diploma, mas a reprodução de igual dispositivo da Carta de 67, art. 96, "não se admitirá vinculação ou equiparaçāo de qualquer natureza para o efeito de remuneração do pessoal do serviço público". De modo que, ao ser promulgada a Constituição de 88 , fazia mais de vinte anos que esse preceito figurava em nosso direito positivo, e não impediu que procuradores autárquicos e procuradores do Estado de São Paulo tivessem o mesmo tratamento pecuniário, especificamente, percebessem ambos a mesma verba honorária, nāo porque houvesse vinculaçāo entre eles, mas dada a evidente identidade de funções, ou na pior de todas as hipóteses, inegável semelhança de funçōes, atribuiçōes e finalidades. Como sabido, a pluralidade de agentes não exclui a unidade da ação administrativa.

\section{ANTES DA CONSTITUIÇÃO PAULISTA}

29. Segundo informa a consulente, já em 1959, quando a Procuradoria Geral do Estado se denominava Departamento Jurídico do Estado, foi reconhecido a procuradores autárquicos do Departamento Estadual de Rodagem a verba honorária percebida pelos procuradores do Estado; em 1974, pela Lei Complementar 93, com a redaçāo da Lei Complementar 205, ficou estipulado o pagamento da questionada verba honorária aos Procuradores do Estado, devendo o Governador do Estado em 90 dias, regulamentar o pagamento de igual vantagem aos procuradores autárquicos; como o prazo se escoasse sem a regulamentação prevista, várias açōes foram ajuizadas no foro estadual e uma delas, pelo menos, chegou ao Supremo Tribunal Federal, por via do RE 104.252-4, relator o Sr. Ministro NERI DA SILVEIRA; 
em acórdāo unânime, de 2.11.93. Diário da Justiça de 18.6.93, pág. 12.113, Ementário n 1708-04, ficou assentado:

"EMENTA: Recurso extraordinário. Procuradores autárquicos paulistas. Pretensão a receber quotas correspondentes a honorários de advogado, em idênticos valores às percebidas pelos integrantes da carreira de Procurador do Estado. Lei Complementar $n^{\circ} 93$, de 28.05.1974, com a redação dada pela Lei Complementar $n^{\circ} 205$, de 02.01.1979 (art. 82), ambas do Estado de São Paulo. $O$ acórdão reconheceu o direito dos autores somente a partir do Decreto estadual $n^{\circ} 19.866$, de 09.11 .1982 , e não a contar de noventa dias da Lei Complementar $n^{\circ}$ 205/1979 (art. 82) O Decreto $n^{\circ} 19.866$, de 1982 , em nada modificou os presssupostos à outorga da vantagem, nem especificou condições especiais a seu cálculo. Dessa maneira, nada justifica a não-concessão do beneficio contemplado em lei, após o decurso do prazo para a expedição do decreto previsto no art. 82, da Lei Complementar paulista $n^{\circ} 205 / 1979$. Recurso extraordinário conhecido e provido, para restaurar a decisão de primeiro grau."

Mais tarde, em 1986, por iniciativa do Governador do Estado, a Assembléia aprovou a Lei Complementar 478, Lei Orgânica da Procuradoria Geral do Estado, regulamentada pelo Decreto 26.233 , que, nos artigos $6^{\circ}$ e $8^{\circ}$, reiterou a orientação vintenária.

30. Como se vê, a percep̧̧ão da verba honorária, assim pelos procuradores autárquicos, como pelos procuradores do Estado, é anterior à Constituiçāo Estadual de 1989 e independente do seu art. 101; o fato é incontroverso e está solenemente comprovado até pelo Supremo Tribunal Federal.

31. Ora, segundo lição corrente, a Constituição não representa uma ruptura com o sistema jurídico anterior e deve ser construída tendo em vista a legislação ordinária preexistente, BLACK, Construction and Interpretation of the Laws, $n^{\circ} 11$, pág. 19; id., Constitutional Law, 1910, $\mathbf{n}^{\circ}$ 49, pág. 78; WILLOUGHBY, op. cit., I, § 28, pág. 49; AURELINO LEAL, Teoria e Prática da Constituição
Federal, 1925, I, pág. 9; na frase de RUY BARBOSA, "uma regra de interpretação constitucional na jurisprudência americana quer que as constituiçōes se entendam à luz da legislação preexistente no país", Obras Completas, XXIII, 1896, III, pág. 238.

32. A igualdade de tratamento pecuniário dos procuradores do Estado e de suas autarquias, fazia muito, estava consagrada na legislação e na prática administrativa do Estado de São Paulo. Sobrevindo a Constituição de 1989, esta, sem inovar, reiterou e confirmou esse tratamento legal. Tenho isto como induvidoso. Não se trata de uma opiniāo, mas de um dado da realidade, de um fato objetivo e comprovado.

Ora, como é sabido, a prática constitucional longa e uniformemente aceita pelo Poder Legislativo ou pelo Executivo tem mais valor para o intérprete do que as especulaçōes de espíritos engenhosos, para repetir STORY, op. cit., I, § 408, pág. 312, e MAXIMILIANO, Comentários, $\mathrm{n}^{\circ} 80$, pág. 109, e o Corpus Juris Secundum, 1956, v. 16, § 32, pág. 105; 1984, v. $16 \S 33$, pág. 102.

33. Assim sendo, a intangibilidade da remuneração dos procuradores autárquicos é inequivoca, mas menos decorre do art. 101 da Constituição paulista, que da Constituição Federal a ela anterior, e que, em cláusula expressa, consagrou a irredutibilidade de vencimentos, art. $37, \mathrm{XV}$, tese anteriormente sustentada por PONTES DE MIRANDA, op. cit., III, pág. 433.

34. Pelo exposto, o que me parece difícil não é reconhecer a igualdade de tratamento pecuniário entre segmentos homogêneos do serviço jurídico do Estado, ao ponto de a Lei Orgânica da Procuradoria Geral do Estado mandar aplicar seus dispositivos, no que couber, aos procuradores autárquicos, mas negar o tratamento igualitário quanto a "vencimentos, vantagens", ao mesmo passo em que reconhece a igualdade em "direitos e deveres, garantias e prerrogativas, proibiçōes e impedimentos, atividade correicional e disposifões atinentes à carreira de Procurador do Estado", art. 101, da Constituição estadual. 


\section{CONCLUSÃO}

35. Não vejo a mais leve nódoa no artigo 101 da Constituiçāo do Estado de São Paulo, seja em seu todo, seja nas expressões "vencimentos, vantagens", nas quais, por fim, se concentrou a impugnação por alegada ofensa aos artigos 37, XIII e 61, § $1^{\circ}$, II, "a", da Constituição Federal.

O disposto no artigo 101, "vinculam-se à Procuradoria Geral do Estado, para fins de atuação uniforme e coordenada, os órgãos jurídicos das autarquias", decorre do enunciado no artigo 98 da mesma Constituição estadual, “a Procuradoria Geral do Estado é ... responsável pela Advocacia do Estado, da Administração direta e autarquias", e ambos prestam homenagem à unidade orgânica e funcional dos serviços jurídicos do Estado, sejam eles da administração direta, sejam das autarquias.

O tratamento pecuniário dado aos procuradores do Estado e aos procuradores autárqui- cos, inclusive no tocante à verba honorária, não foi instituído pelo artigo 101 da Constituição paulista, pois anos antes de sua promulgação estava consagrado em leis complementares estaduais e adotado na prática administrativa.

O direito dos procuradores autárquicos ao tratamento pecuniário estabelecido antes da Constituição Federal é intangível, não pelo que diz o artigo 101, da Constituição do Estado, mas pelo que a Lei maior assegurou a civis e militares, a irredutibilidade de vencimentos, artigo $37, \mathrm{XV}$.

Não me parece juridicamente possível desfazer-se um direito fundado na Constituição Federal mediante ação de inconstitucionalidade contra artigo de Constituição estadual.

É o meu parecer.

Porto Alegre, 5 de dezembro de 1997.

PAULO BROSSARD DE SOUZA PINTO

Ministro aposentado do Supremo Tribunal Federal 